\title{
Adherence to Highly Active Antiretroviral Therapy and Its Association with Serostatus Disclosure among People Living with HIV in Ethiopia: A Systematic Review and Meta-Analysis.
}

Abere Woretaw Azagew ( $\nabla$ wabere@ymail.com )

University of Gondar https://orcid.org/0000-0002-6270-5992

Chilot Kassa Mekonnen

University of Gondar

Abebaw Jember Ferede

University of Gondar

Kassahun Gebeyehu Yazew

University of Gondar

\section{Zewdu Baye Tezera}

University of Gondar

\section{Research article}

Keywords: HAART, ART, Adherence, HIV disclosure, Adult HIV positive

Posted Date: November 16th, 2020

DOI: https://doi.org/10.21203/rs.3.rs-18608/v2

License: (a) (1) This work is licensed under a Creative Commons Attribution 4.0 International License.

Read Full License 


\section{Abstract}

Background: Adherence to highly active antiretroviral therapy (HAART) is a public health challenge worldwide. Non-adherence to HAART leads to treatment, immunologic, and virological failure. Despite different interventions made, adherence to HAART among adult people living with HIV (PLWHIV) is still inconsistent across studies, and the effect of serostatus disclosure on adherence to HAART was not studied in Ethiopia. Therefore, the study is aimed to determine the pooled prevalence of adherence to HAART and its relationship with serostatus disclosure among adult PLWHIV in Ethiopia.

Methods: We searched 3247 original articles, both published and unpublished on Ethiopia dated from January 2016 to November 2019 by using different search engines. Data were extracted using Microsoft excel. New Castle Ottawa Scale quality assessment tool was used. STATA software version 11 was used for analysis. A random-effects model for meta-analysis was computed. Cochran $Q$ statistics and $\mathrm{I}^{2}$ were used to estimate heterogeneity. Egger's and Begg's test was used to assess the publication bias.

Results: A total of fifteen articles for systematic review and four articles for meta-analysis were used. The pooled prevalence of adherence to HAART is found to be $81.19 \%(80.1,82.3)$. In the subgroup analysis, the pooled prevalence of adherence to HAART was $79.82 \%(73.19,86.45)$ in the Oromia region, $82.51 \%($ $73.14,91.87)$ in the Amhara region, and $72.7 \%(63.78,81.61)$ in the Southern Nations Nationalities and Peoples' Region (SNNPR). The serostatus disclosure improves adherence to HAART by nearly three times compared to non-serostatus disclosed PLWHIV (AOR=2.99, $95 \% \mathrm{Cl}: 1.88,4.77)$.

Conclusions: The pooled prevalence of adherence to HAART among adult PLWHIV in Ethiopia was found to be low compared to WHO antiretroviral treatment recommendations. Having serostatus disclosure improved adherence to HAART.

\section{Background}

The human immunodeficiency virus(HIV) affects many segments of the world's population in different ways(1). Africa, Asia, and Latin America are the major continents affected by HIV(2). In this regard in 2016, there were about 36.7 million people living with HIV(3).

Globally and in Sub-Saharan Africa there were 160,000 and 110,000 children infected with HIV in different ways respectively (2-4). According to the WHO report in 2016, an estimated 2.1 million adolescents were living with HIV, and of this $84 \%$ were living in Sub-Saharan Africa(SSA)(5). The SSA is home for $76 \%$ of the global morbidity and $75 \%$ of mortality caused by HIV/AIDS(6). In Ethiopia in 2018, around 690,000 people living with HIV, 23,000 were newly infected, and 11,000 people died from an AIDS-related illness. Ethiopia launched its ART initiatives in 2003 based on a subsidized fee-based approach, and it became available free of charge in 2005. As a result, the number of ART users has increased from 47,422 in 2005 to 703, 516 in 2017(7). The United Nations set goals on the HIV/AIDS epidemic prevention named the 9090-90 target indicating $90 \%$ of people who are HIV infected will be diagnosed, $90 \%$ of people who are diagnosed with HIV will be on antiretroviral treatment, and $90 \%$ of those who received antiretroviral 
treatment will be virally suppressed $(8,9)$. Adherence to highly active antiretroviral therapy (HAART) can prolong the life of HIV patients(10). On the contrary, non-adherence to antiretroviral therapy(ART) could lead to different complications such as treatment, immunological, and virological failure $(11,12)$. HIV infection does not only affect the patient but also the families, communities, and the country at large (2, 6). Antiretroviral therapy has a clinical effect in decreasing viral replication and viral load which in turn increases the CD4 level and decreases the progress of HIV/AIDS(13). The clinical outcome of PLWHIV depends on adherence to antiretroviral therapy (ART). Studies showed that adherence to HAART accurately predicted the prognosis of AIDS and death(12,14). Level of awareness about HIV, counseling about adherence, a substance used, side effects of the ART, and depression hinder the adherence to HAART (15-18). Serostatus disclosure may also attribute to adherence to HAART. Sharing one's own HIV positive diagnostic test result to a partner, family members, and friends provide the patient to take their ART medication freely(19). As far as known, there is no published systematic review and meta-analysis study on adherence to HAART among adult PLWHIV in Ethiopia. The finding of this study will strengthen adherence to HAART services and national HIV/AIDS control programs. Therefore, the study is aimed to determine the pooled prevalence of adherence to HAART and the effect of serostatus disclosure on adherence to HAART among adult PLWHIV in Ethiopia.

\section{Methods}

\section{Study design and searching strategy}

The study employed two systematic reviews/meta-analyses: one to analyze the prevalence of adherence to HAART and another to review for the role of serostatus disclosure on ART adherence. These systematic review/meta-analysis studies were carried out on published and unpublished literatures to determine the pooled prevalence of adherence to HAART among adult PLWHIV in Ethiopia. Studies were found through electronic and manual searches using databases; PSYCH INFO, EMBASE, MEDLINE/Pubmed, Google Scholar, and Google for gray literature.

Articles were searched using the following searching terms; "adherence", "nonadherence", "compliance", "noncompliance", "missing dose", "highly active antiretroviral therapy", "HAART”,"antiretroviral therapy","ART”, "adult people living with HIV”, "adult PLWHIV”, "adult HIV positive patients", "HIV disclosure", "serostatus disclosure", and "Ethiopia", the articles were restricted to the publication date from January 2016 to November 2019 studied in Ethiopia.

\section{Inclusion and Exclusion Criteria}

Those published/unpublished articles in Ethiopia on adult PLWHIV from January 2016 to November 2019 in the English language were searched. Articles that report the prevalence of adherence/non-adherence to HAART/ART and/or articles that show the association of serostatus disclosure to adherence to HAART/ART were included in the study. Conference papers, articles without full texts, and qualitative studies were excluded from the study. 


\section{Data extraction}

Two reviewers (AWA \& ZBT) screened the titles and abstracts of identified studies and assessed the full text of potentially eligible studies. Any controversy was resolved by consensus. An effort was made to communicate with the authors' whenever further information was needed. Data were extracted independently by these reviewers. Data on the author(s), study year/year of publication, the region of study, study design, adherence status, sample size, and HIV serostatus disclosure such as odds ratio and standard error were extracted using Microsoft excel. The adherence status to HAART and the association of serostatus disclosure on adherence to HAART among adult PLWHIV in Ethiopia was extracted from each included study by CKM, KGY, and AJF. The whole manuscript was critically reviewed by all authors.

\section{Quality Appraisal}

Articles were assessed for quality score using the New Castle Ottawa Scale adapted for cross-sectional studies quality assessment tool with a score of $\geq 5$ out of 10 , considered as high-quality score(20). Two authors (AWA \& ZBT) assessed the quality of each paper. The reviewers compared the quality of appraisal scores and resolved inconsistencies prior to calculating the final appraisal score. All included studies had a high quality of scores. The preferred reporting items of systematic review and metaanalysis (PRISMA) guideline(21) was used to report the result of this study.

\section{Data analysis}

Data were analyzed using STATA version 11. The summary effect estimates of the prevalence were calculated by using a meta-analysis in a random effect model. Cochrane $\mathrm{Q}$ statistics and $\mathrm{I}^{2}$ were used to estimate the presence of heterogeneity. $\left.\right|^{2}$ test statistic results of $25 \%, 50 \%$, and $75 \%$ were declared as low, moderate, and high heterogeneity respectively(22). Subgroup analyses by region were done to estimate the regional variations in the adherence status to HAART. Sensitivity analysis was used to see the discrepancy among studies. Egger's and Begg's test was used to estimate the publication bias. Trim and fill analysis was used to treat the potential publication bias.

\section{Results}

\section{Selection and Identification of studies}

A total of 3247 studies conducted in Ethiopia were retrieved, and of which 3082 studies were rejected just by reading their titles. Of the remaining 165 studies, 147 were excluded after reviewing the abstracts. Full-text articles of 18 studies that met or potentially met the inclusion criteria were assessed. After further screening, 15 articles were retained for inclusion for the systematic review. Of 15 studies included in the systematic review, 11 studies were excluded and 4 (23-26) articles were used for meta-analysis (Fig 1).

\section{Characteristics of the articles}


Of the fifteen full studies; eight of them were conducted in the Oromia region, three in the Amhara region, two in the SNNPR, one in Harar, and one in Addis Ababa. Relevant features of each study such as author, year of publication, the region of study, study design, study population, sample size, adherence status to HAART, and the association of serostatus disclosure to HAART were extracted. The majority of the articles' adherent status to HAART was measured using self-report and taking $\geq 95 \%$ of the prescribed doses of medication is considered as good adherence to HAART (Table 1).

Table 1: General characteristics of included studies that report the adherence status to HAART and/its association with HIV disclosure status. 


\begin{tabular}{|c|c|c|c|c|c|}
\hline Author/ Year & Region & $\begin{array}{l}\text { Adherence to } \\
\text { measurement }\end{array}$ & Adherence definition & $\begin{array}{l}\text { Sample } \\
\operatorname{size}(n)\end{array}$ & $\begin{array}{l}\text { Adherence to } \\
\text { HAART (\%) }\end{array}$ \\
\hline $\begin{array}{l}\text { Dibaba et } \\
\text { al./2016(27) }\end{array}$ & Oromia & self-report & $100 \%$ & 306 & 65 \\
\hline $\begin{array}{l}\text { Hassen et } \\
\text { al./2019(28) }\end{array}$ & Oromia & self-report & $\geq 95 \%$ of the prescribed doses & 352 & 73.6 \\
\hline $\begin{array}{l}\text { Molla et } \\
\text { al./2018(23) }\end{array}$ & Amhara & pill count & $\geq 95 \%$ of the prescribed doses & 440 & 88.2 \\
\hline $\begin{array}{l}\text { Negasa et } \\
\text { al./2017(29) }\end{array}$ & Harar & self-report & $100 \%$ & 314 & 65 \\
\hline $\begin{array}{l}\text { Nuredin et } \\
\text { al./2017(30) }\end{array}$ & SNNPR & $\begin{array}{l}\text { self-report and } \\
\text { pharmacy refill }\end{array}$ & $\geq 95 \%$ of the prescribed doses & 428 & 77.1 \\
\hline $\begin{array}{l}\text { Efrem et } \\
\text { al./2016(31) }\end{array}$ & Oromia & self-report & $100 \%$ & 383 & 89.3 \\
\hline $\begin{array}{l}\text { Naod et } \\
\text { al./2017(32) }\end{array}$ & $\begin{array}{l}\text { Addis } \\
\text { Ababa }\end{array}$ & self-report & $\geq 95 \%$ of the prescribed doses & 273 & 80.1 \\
\hline $\begin{array}{l}\text { Kassahun et } \\
\text { al./2017(33) }\end{array}$ & Oromia & self-report & $\geq 95 \%$ of the prescribed doses & 321 & 72.3 \\
\hline \multirow[t]{2}{*}{$\begin{array}{l}\text { Hailu et } \\
\text { al./2018(34) }\end{array}$} & SNNPR & pill count & $\geq 95 \%$ of the prescribed doses & 320 & 68 \\
\hline & & & & 190 & 92.6 \\
\hline $\begin{array}{l}\text { Wendwesen et } \\
\text { al./2017(25) }\end{array}$ & Oromia & $\begin{array}{l}\text { self-report and record } \\
\text { review }\end{array}$ & $>95 \%$ of prescribed doses & & \\
\hline $\begin{array}{l}\text { Shewaye et } \\
\text { al./2016(24) }\end{array}$ & Oromia & self-report & $100 \%$ & 420 & 86 \\
\hline $\begin{array}{l}\text { Tesfaye et } \\
\text { al./2019(35) }\end{array}$ & Amhara & self-report & $\geq 95 \%$ of the prescribed doses & 418 & 71.8 \\
\hline $\begin{array}{l}\text { Jima et } \\
\text { al./2018(36) }\end{array}$ & Oromia & self-report & $\begin{array}{l}\text { as per Robinson et al(37)adherence } \\
\text { measurement }\end{array}$ & 160 & 85.6 \\
\hline Abadiga /2019(26) & Oromia & pill count & $\geq 95 \%$ of the prescribed doses & 305 & 73.1 \\
\hline $\begin{array}{l}\text { Mengstie } \\
/ 2018(38)\end{array}$ & Amhara & self-report & $\geq 95 \%$ of the prescribed doses & 352 & 87.2 \\
\hline
\end{tabular}

Notes; Study design; Cross-sectional, Study population; Adult People Living with HIV; HAART; Highly active antiretroviral therapy, SNNPR; Southern Nations Nationalities and peoples' region 


\section{Adherence to HAART}

Among 15 cross-sectional studies, the prevalence of adherence to HAART ranged from $65 \%(27,29)$ to $92.6 \%(25)$. The overall pooled prevalence of adherence to HAART is found to be $81.2 \%(80.1-82.3)$ (Table 2). Based on subgroup analysis by region, the pooled prevalence of adherence to HAART was $79.82 \%$ $(73.19,86.45)$ in the Oromia region, $82.51 \%(73.14,91.87)$ in the Amhara region, and $72.7 \%(63.78$, 81.61) in the SNNPR (Fig 2).

Table 2: The pooled prevalence of adherence to HAART among adult people living with HIV in Ethiopia.

\begin{tabular}{|c|c|c|c|c|}
\hline Author/Year & ES & \multicolumn{2}{|l|}{$[95 \% \mathrm{CI}]$} & $\%$ Weight \\
\hline Dibaba et al. (2016) & 65. & 59.7 & 70.3 & 3.9 \\
\hline Hassen et al. (2019) & 73.6 & 69 & 78.2 & 5.3 \\
\hline Molla et al. (2018) & 88.2 & 85.2 & 91.2 & 12.3 \\
\hline Negasa et al. (2017) & 65 & 59.7 & 70.3 & 4.0 \\
\hline Nuredin et al. (2017 & 77.1 & 73.1 & 81.1 & 7.1 \\
\hline Efrem et al. (2016) & 89.3 & 86.204 & 92.4 & 11.7 \\
\hline Naod et al. (2017) & 80.1 & 75.364 & 84.8 & 5.0 \\
\hline Kassahun et al. (2017) & 72.3 & 67.404 & 77.2 & 4.7 \\
\hline Hailu et al (2018) & 68 & 62.889 & 73.1 & 4.3 \\
\hline Wendwesen et al.(201 & 7) 92.6 & 88.878 & 96.3 & 8.1 \\
\hline Shewaye et al. (2016) & 86 & 82.682 & 89.3 & 10.2 \\
\hline Aychew et al (2019) & 71.8 & 67.486 & 76.1 & 6.0 \\
\hline Jima etal. (2018) & 85.6 & 80.160 & 91. & 3.8 \\
\hline Abadiga (2019) & 73.1 & 68.123 & 78.1 & 4.5 \\
\hline Mengstie (2018) & 87.2 & 83.710 & 90.7 & 9. \\
\hline I-V pooled ES & 81.2 & 80.1 & 82.3 & 100 \\
\hline \multicolumn{5}{|c|}{ Heterogeneity chi-squared $=257.96($ d.f. $=14) p=0.000$} \\
\hline \multicolumn{5}{|c|}{ I-squared (variation in ES attributable to heterogeneity) $=94.6 \%$} \\
\hline \multicolumn{5}{|c|}{ Test of $E S=0: z=150.39 p=0.000$} \\
\hline
\end{tabular}

Notes: CI; Confidence Interval, DF; Degree of Freedom, ES; Effect Size

\section{Heterogeneity test}


As shown in the table, the heterogeneity test $\left(\mathrm{I}^{2}\right)$ is $94.6 \%$. This indicates there is a considerable variation across studies but the sensitivity analysis indicates there is no study apart from lower and upper confidence intervals. All the studies concentrated around the point of the estimation. The funnel plot test is asymmetrical (Fig 3).

\section{Publication bias}

Publication bias was detected based on the graphic asymmetry of funnel plots, egger's test $(p<0.05)$, and Begg's test. In the Egger test, the $p$-value is 0.001 which shows that there is a publication bias. Therefore, the authors used a random effect model to treat bias. Furthermore, the trim and fill analysis was also computed.

\section{The effects of Serostatus Disclosure on Adherence to HAART}

To determine the effects of serostatus disclosure on adherence to HAART among PLWHIV in Ethiopia, a total of four cross-sectional studies (23-26) were used. This study revealed that clients who disclosed their serostatus to someone else are nearly three times more likely to adhere to their HAART compared to clients who did not disclose their serostatus(AOR= 2.99, 95\%Cl: 1.88, 4.77)(Fig 4).

\section{Heterogeneity}

The heterogeneity test $\left(1^{2}\right)$ is $51.8 \%$ which indicates there is a considerable variation across studies. The funnel plot test is symmetrical. The sensitivity test indicates there is no study apart from lower and upper confidence intervals. All the studies concentrated around the point of the estimation.

\section{Publication bias}

Publication bias was detected based on the graphic asymmetry of the funnel plot and egger's test $(\mathrm{p}<$ 0.05 ). The test indicates the graphic funnel plot is symmetrical and the egger's plot test result is 0.063 .

\section{Discussion}

Adherence to the prescribed HAART is considered as a parameter for successful long-term management of HIV infection. Fifteen-cross sectional studies conducted in Ethiopia were used for this review study and from which four articles were used for meta-analysis. The prevalence of adherence to HAART ranged from $65 \%$ to $96.2 \%$. In this systematic review, the pooled prevalence of adherence to HAART was found to be $81.2 \%$ (80.1-82.3). In the subgroup analysis, the pooled prevalence of adherence to HAART was 79.82 $\%(73.19,86.45)$ in the Oromia region, $82.51 \%(73.14,91.87)$ in the Amhara region, and $72.7 \%(63.78$, $81.61)$ in the SNNPR. Our study finding is higher in a study conducted in $>26$ countries reviewed study with an adherence rate to HAART was $63 \%(39)$, India $70 \%(40), 62.3 \%$ a study reviewed on 53 countries (41). The discrepancy is due to variation in adherence measurement tool, the use of multiple interventions, and use of clinical trials. The finding of this review study is lower than a study conducted in Tanzania and Botswana, $98 \%$ and $93 \%(42,43)$ respectively. The discrepancy is due to the fact that the 
former studies are small sampled studies compared to this reviewed study. Furthermore, the finding of this study is lower than the national ART treatment guideline $\geq 95 \%$ (44) and other reviewed studies conducted on 20 countries $90 \%$ (45), but the population were homosexual men.

The finding of this study revealed that serostatus disclosure improved adherence to HAART nearly by three times compared to those who did not serostatus disclosed ART users (AOR=2.99, 95\%Cl: 1.88 , 4.77). The serostatus disclosure is an adherence enhancing intervention (46). The study is supported by a global evidence study using a treatment supporter that enhances adherence to HAART (47). Using adherence to HAART supporter is a tool/an intervention for viral load suppression (48). A study was done on developed and developing nations' fear of serostatus disclosure and suspicion on treatment which resulted in decrease adherence to HAART (49). The serostatus disclosure to others results in a higher rate of adherence to HAART (19). HIV serostatus disclosing relieves stress and anxiety, providing a trusting relationship between the patient and supporter, and sharing positive messages(44). The authors used articles solely studied in Ethiopia. Further research is recommended by incorporating other African studies and numbers of factors.

\section{Conclusion}

The pooled prevalence of adherence to HAART among adult PLWHIV in Ethiopia was found to be low compared to $\mathrm{WHO}$ antiretroviral treatment recommendations. Having serostatus disclosure improved adherence to HAART. Adherence to HAART and serostatus disclosure have a role in the treatment outcome of HIV patients. Successful treatment of HIV/AIDS with HAART improves a patient's CD4 count and decreases viral load.

\section{Abbreviations}

AIDS; Acquired Immune Deficiency Syndrome, AOR; Adjusted Odds Ratio, ART; Antiretroviral Therapy, HAART; Highly Active Antiretroviral Therapy, HIV; Human immune deficiency Virus, PLWHIV; People Living With Human Immune-deficiency Virus

\section{Declarations}

\section{Ethical Approval and consent to participate}

Not applicable because no primary data collected

\section{Consent for publication}

Not applicable

\section{Availability of data and Material}


The datasets used and/or analyzed during the current study are available from the corresponding author on reasonable request.

\section{Competing interest}

The authors declare that there is no competing of interest

\section{Funding}

The authors' did not receive any funding

\section{Authors' contribution}

AWA conceived the idea and design this research work. CKM, AJF, KGY, and ZBT participated in the data extraction, analysis, and interpretation. All the authors approved the final draft of the manuscript.

\section{Acknowledgments}

Our special gratitude goes to the authors of the included studies which help us to do this systematic review and meta-analysis.

\section{References}

1. Cohen MS, Hellmann N, Levy JA, DeCock K, Lange J. The spread, treatment, and prevention of HIV-1: evolution of a global pandemic. The Journal of clinical investigation. 2008;118(4):1244-54.

2. Hamilton E, Bossiky B, Ditekemena J, Esiru G, Fwamba F, Goga AE, et al. Using the PMTCT cascade to accelerate achievement of the global plan goals. Journal of acquired immune deficiency syndromes (1999). 2017;75(1):S27.

3. Unaids J. Fact sheet-latest global and regional statistics on the status of the AIDS epidemic. Geneva: UNAIDS. 2017.

4. Organization WH. Progress report 2016: prevent HIV, test and treat all: WHO support for country impact. World Health Organization, 2016.

5. Slogrove AL, Sohn AH. The global epidemiology of adolescents living with HIV: time for more granular data to improve adolescent health outcomes. Current Opinion in HIV and AIDS. 2018;13(3):170-8.

6. Fullman N, Barber RM, Abajobir AA, Abate KH, Abbafati C, Abbas KM, et al. Measuring progress and projecting attainment on the basis of past trends of the health-related Sustainable Development Goals in 188 countries: an analysis from the Global Burden of Disease Study 2016. The Lancet. 2017;390(10100):1423-59.

7. Barnabas G, Sibhatu MK, Berhane Y. Antiretroviral therapy program in Ethiopia benefits from virology treatment monitoring. Ethiopian journal of health sciences. 2017;27(1):1-2. 
8. Gottlieb GS, Raugi DN, Smith RA. 90-90-90 for HIV-2? Ending the HIV-2 epidemic by enhancing care and clinical management of patients infected with HIV-2. The Lancet HIV. 2018;5(7):e390-e9.

9. Wong VJ, Murray KR, Phelps BR, Vermund SH, McCarraher DR. Adolescents, young people, and the 90-90-90 goals: a call to improve HIV testing and linkage to treatment. AIDS (London, England). 2017;31(Suppl 3):S191.

10. Yared M, Tibebu S, Emmart P. Equity and Access to ART in Ethiopia Washington: Initiative HP 2010 Futures Group. Task Order. 2010;1.

11. Gesesew HA, Ward P, Hajito KW, Feyissa GT, Mohammadi L, Mwanri L. Discontinuation from antiretroviral therapy: a continuing challenge among adults in HIV care in Ethiopia: a systematic review and meta-analysis. PloS one. 2017;12(1):e0169651.

12. Oguntibeju 0O. Quality of life of people living with HIV and AIDS and antiretroviral therapy. HIV/AIDS (Auckland, NZ). 2012;4:117.

13. Mayer KH, Shisana O, Beyrer C. AIDS 2016: from aspiration to implementation. The Lancet. 2016;387(10037):2484-5.

14. Nachega JB, Hislop M, Nguyen H, Dowdy DW, Chaisson RE, Regensberg L, et al. Antiretroviral therapy adherence, virologic and immunologic outcomes in adolescents compared with adults in southern Africa. Journal of acquired immune deficiency syndromes (1999). 2009;51(1):65.

15. Biressaw S, Abegaz WE, Abebe M, Taye WA, Belay M. Adherence to Antiretroviral Therapy and associated factors among HIV infected children in Ethiopia: unannounced home-based pill count versus caregivers' report. BMC pediatrics. 2013;13(1):132.

16. Letta S, Demissie A, Oljira L, Dessie Y. Factors associated with adherence to Antiretroviral Therapy (ART) among adult people living with HIV and attending their clinical care, Eastern Ethiopia. BMC international health and human rights. 2015;15(1):33.

17. Silva JAG, Dourado I, Brito AMd, Silva CALd. Factors associated with non-adherence to antiretroviral therapy in adults with AIDS in the first six months of treatment in Salvador, Bahia State, Brazil. Cadernos de saude publica. 2015;31(6):1188-98.

18. Gebrezgabher BB, Kebede Y, Kindie M, Tetemke D, Abay M, Gelaw YA. Determinants to antiretroviral treatment non-adherence among adult HIV/AIDS patients in northern Ethiopia. AIDS research and therapy. 2017;14(1):16.

19. Stirratt MJ, Remien RH, Smith A, Copeland OQ, Dolezal C, Krieger D, et al. The role of HIV serostatus disclosure in antiretroviral medication adherence. AIDS and Behavior. 2006;10(5):483-93.

20. Moskalewicz A, Oremus M. No clear choice between Newcastle-Ottawa Scale and Appraisal Tool for Cross-Sectional Studies to assess methodological quality in cross-sectional studies of health-related quality of life and breast cancer. Journal of Clinical Epidemiology. 2020;120:94-103.

21. Liberati A, Altman DG, Tetzlaff J, Mulrow C, Gøtzsche PC, loannidis JP, et al. The PRISMA statement for reporting systematic reviews and meta-analyses of studies that evaluate health care interventions: explanation and elaboration. Journal of clinical epidemiology. 2009;62(10):e1-e34. 
22. Higgins JP, Thompson SG, Deeks JJ, Altman DG. Measuring inconsistency in meta-analyses. Bmj. 2003;327(7414):557-60.

23. Molla AA, Gelagay AA, Mekonnen HS, Teshome DF. Adherence to antiretroviral therapy and associated factors among HIV positive adults attending care and treatment in University of Gondar Referral Hospital, Northwest Ethiopia. BMC infectious diseases. 2018;18(1):266.

24. Fituma S. HIV Positive Status Disclosure and Highly Active Antiretroviral therapy Adherence among People living with HIV in Ambo Hospital, West Shewa Zone, Oromia Region, Ethiopia: Addis Abeba Universty; 2016.

25. Abayneh W, Obse N, Naba T. Factors Associated With Level of Adherence to Antiretroviral Therapy in People Living with HIV/AIDS at Adama Hospital Medical College Art Clinic, Oromiya Regional State, Ethiopia. International Journal of HIV/AIDS Prevention, Education and Behavioural Science. 2017;3(3):22-7.

26. Abadiga M. ADHERENCE TO ANTIRETROVIRAL THERAPY AND ASSOCIATED FACTORS AMONG HIV POSITIVE ADULTS ATTENDING TREATMENT AT NEKEMTE REFERRAL HOSPITAL, WEST ETHIOPIA. infectious diseases 2019.

27. Dibaba B, Hussein M. Factors associated with non-adherence to antiretroviral therapy among adults living with HIV/AIDS in Arsi zone, Oromia. Journal of AIDS and Clinical Research. 2017;8(1).

28. Hassen A, Mohammed Y. Antiretroviral Therapy Adherence Level and Associated Factors Among HIV/AIDS Patients in Jimma Zone Government Health Facilities, ART Clinics, South-west Ethiopia. International Journal of Multicultural and Multireligious Understanding. 2019;5(5):331-41.

29. Negesa L, Demeke E, Mekonnin W. Adherence to Antiretroviral Therapy and Factors affecting among People Living with HIV/AIDS and Taking Antiretroviral Therapy, Dire Dawa Town, Eastern Ethiopia. J Infect Dis Treat. 2017;3(1):5.

30. Azmach NN. Adherence to Antiretroviral Therapy and Associated Factors Among Adult ARV Users in Arba Minch Hospital, Southern Ethiopia.

31. Negash E, Wakgari N, Wasie B, Edris M, Bekele G. Adherence to antiretroviral therapy and its associated factors among HIV positive patients in Nekemte public health institutions, West Ethiopia. HIV \& AIDS Review. 2016;15(3):116-21.

32. Firdu N, Enquselassie F, Jerene D. HIV-infected adolescents have low adherence to antiretroviral therapy: a cross-sectional study in Addis Ababa, Ethiopia. Pan African Medical Journal. 2017;27(1).

33. Bidu KT, Babure ZK. Barriers of adherence to antiretroviral therapy among HIV/AIDS infected persons in Nekemte referral Hospital, East Wollega, Oromia Regional State, Western Ethiopia, 2017. Journal of AIDS and HIV Research. 2018;10(5):64-76.

34. Koyra H. Adherence to Antiretroviral Therapy among Adult Persons Living with HIV/AIDS in Southern Ethiopia. Int J Virol AIDS. 2018;5:038.

35. Legesse TA, Reta MA. Adherence to Antiretroviral Therapy and Associated Factors among People Living with HIV/AIDS in Hara Town and Its Surroundings, North-Eastern Ethiopia: A Cross-Sectional Study. Ethiop J Health Sci. 2019;29(2):447. 
36. Jima F, Tatiparthi R. Prevalence of nonadherence and its associated factors affecting on HIV adults follow-up at antiretroviral therapy clinic in Batu Hospital, Eastern Ethiopia. Indian journal of sexually transmitted diseases and AIDS. 2018;39(2):91.

37. Robinson JH, Callister LC, Berry JA, Dearing KA. Patient-centered care and adherence: Definitions and applications to improve outcomes. Journal of the American Academy of Nurse Practitioners. 2008;20(12):600-7.

38. Mengistie A, Birhane A, Tesfahun E. Assessment of Adherence to Antiretroviral Therapy Among Adult People Living with HIV/AIDS in North East, Ethiopia. BioRxiv. 2018:492330.

39. Bezabhe WM, Chalmers L, Bereznicki LR, Peterson GM. Adherence to antiretroviral therapy and virologic failure: a meta-analysis. Medicine. 2016;95(15).

40. Mhaskar R, Alandikar V, Emmanuel P, Djulbegovic B, Patel S, Patel A, et al. Adherence to antiretroviral therapy in India: a systematic review and meta-analysis. Indian journal of community medicine: official publication of Indian Association of Preventive \& Social Medicine. 2013;38(2):74.

41. Kim S-H, Gerver SM, Fidler S, Ward H. Adherence to antiretroviral therapy in adolescents living with HIV: systematic review and meta-analysis. AIDS (London, England). 2014;28(13):1945.

42. Hardon A, Davey S, Gerrits T, Hodgkin C, Irunde H, Kgatlwane J, et al. From access to adherence: The challenges of antiretroviral treatment: Studies from Botswana, Tanzania and Uganda 2006. 2006.

43. Ramadhani HO, Thielman NM, Landman KZ, Ndosi EM, Gao F, Kirchherr JL, et al. Predictors of incomplete adherence, virologic failure, and antiviral drug resistance among HIV-infected adults receiving antiretroviral therapy in Tanzania. Clinical Infectious Diseases. 2007;45(11):1492-8.

44. Frehiwot N, Mizan K, Seble M, Fethia K, Tekalign M, Zelalem T. National guidelines for comprehensive HIV prevention, care and treatment. Addis Ababa: Ministry of Health. 2014.

45. Ortego C, Huedo-Medina TB, Llorca J, Sevilla L, Santos P, Rodríguez E, et al. Adherence to highly active antiretroviral therapy (HAART): a meta-analysis. AIDS and Behavior. 2011;15(7):1381-96.

46. Kanters S, Park JJ, Chan K, Socias ME, Ford N, Forrest JI, et al. Interventions to improve adherence to antiretroviral therapy: a systematic review and network meta-analysis. The lancet HIV. 2017;4(1):e31e40.

47. Chaiyachati KH, Ogbuoji O, Price M, Suthar AB, Negussie EK, Bärnighausen T. Interventions to improve adherence to antiretroviral therapy: a rapid systematic review. Aids. 2014;28:S187-S204.

48. Bonner K, Mezochow A, Roberts T, Ford N, Cohn J. Viral load monitoring as a tool to reinforce adherence: a systematic review. JAIDS Journal of Acquired Immune Deficiency Syndromes. 2013;64(1):74-8.

49. Mills EJ, Nachega JB, Bangsberg DR, Singh S, Rachlis B, Wu P, et al. Adherence to HAART: a systematic review of developed and developing nation patient-reported barriers and facilitators. PLoS medicine. 2006;3(11):e438.

\section{Figures}




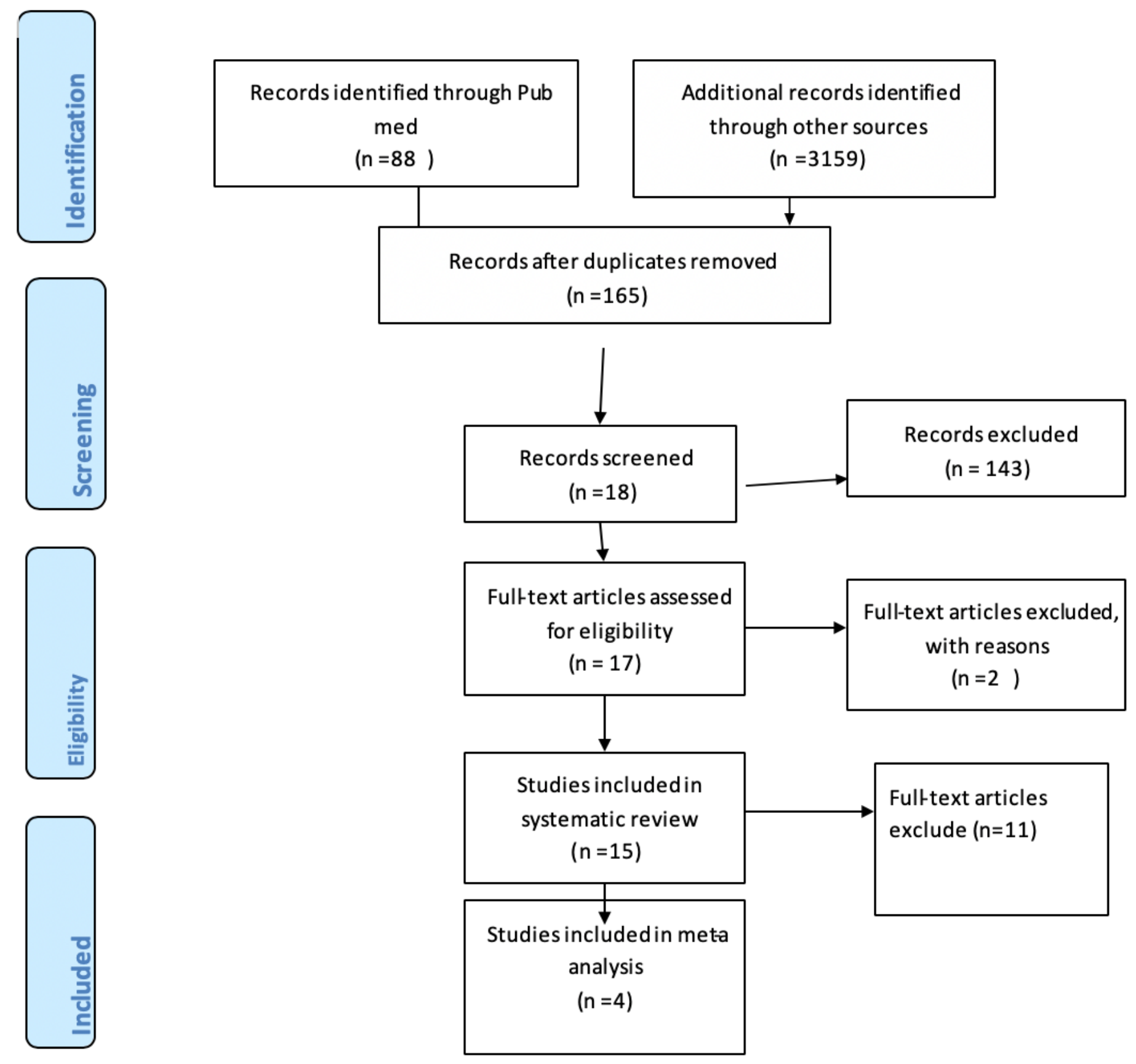

Figure 1

Flow diagram for study selection 


\begin{tabular}{|c|c|c|c|}
\hline \multicolumn{2}{|l|}{ Author } & $\mathrm{ES}(95 \% \mathrm{Cl})$ & $\begin{array}{l}\% \\
\text { Weight }\end{array}$ \\
\hline Oromia & & & \\
\hline Dibaba et al./2016 & $\leftarrow$ & $65.00(59.66,70.34)$ & 6.48 \\
\hline Hassen et al./2019 & $\leftarrow$ & $73.60(69.00,78.20)$ & 6.63 \\
\hline Efrem et al./2016 & & $89.30(86.20,92.40)$ & 6.88 \\
\hline Kassahun et al./2017 & $\rightarrow-1$ & $72.30(67.40,77.20)$ & 6.57 \\
\hline Wendwesen et al./2017 & & $92.60(88.88,96.32)$ & 6.79 \\
\hline Shewaye et al./2016 & & $86.00(82.68,89.32)$ & 6.85 \\
\hline Jima et al./2018 & $i_{1} \rightarrow$ & $85.60(80.16,91.04)$ & 6.46 \\
\hline Abadiga./2019 & $\rightarrow$ & $73.10(68.12,78.08)$ & 6.56 \\
\hline Subtotal $(I-$ squared $=94.9 \%, p=0.000)$ & & $79.82(73.19,86.45)$ & 53.22 \\
\hline \multicolumn{4}{|l|}{ Amhara } \\
\hline Molla et al./2018 & & $88.20(85.19,91.21)$ & 6.89 \\
\hline Aychew et al./2019 & $*$ ! & $71.80(67.49,76.11)$ & 6.69 \\
\hline Mengstie./2018 & & $87.20(83.71,90.69)$ & 6.82 \\
\hline Subtotal (l-squared $=95.2 \%, p=0.000)$ & & $82.51(73.14,91.87)$ & 20.40 \\
\hline Harer & & & \\
\hline Negasa et al./2017 & $\neq \quad 1$ & $65.00(59.72,70.28)$ & 6.50 \\
\hline Subtotal (I-squared $=. \%, p=)$. & $\diamond$ & $65.00(59.72,70.28)$ & 6.50 \\
\hline \multicolumn{4}{|l|}{ SNNPR } \\
\hline Nuredin et al./2017 & $*$ & $77.10(73.12,81.08)$ & 6.74 \\
\hline Hailu et al./2018 & $\rightarrow !$ & $68.00(62.89,73.11)$ & 6.53 \\
\hline Subtotal (I-squared $=86.8 \%, p=0.006$ ) & 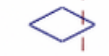 & $72.70(63.78,81.61)$ & 13.27 \\
\hline \multicolumn{4}{|l|}{ Addis Ababa } \\
\hline Naod et al./2017 & $\rightarrow$ & $80.10(75.36,84.84)$ & 6.61 \\
\hline Subtotal $(\mathrm{l}$-squared $=. \%, p=)$. & $\diamond$ & $80.10(75.36,84.84)$ & 6.61 \\
\hline Overall $(I-$ squared $=94.6 \%, p=0.000)$ & 人 & $78.47(73.89,83.06)$ & 100.00 \\
\hline NOTE: Weights are from random effects analysis & i & & \\
\hline
\end{tabular}

Figure 2

Subgroup analysis shows the pooled prevalence of adherence to highly active antiretroviral therapy 


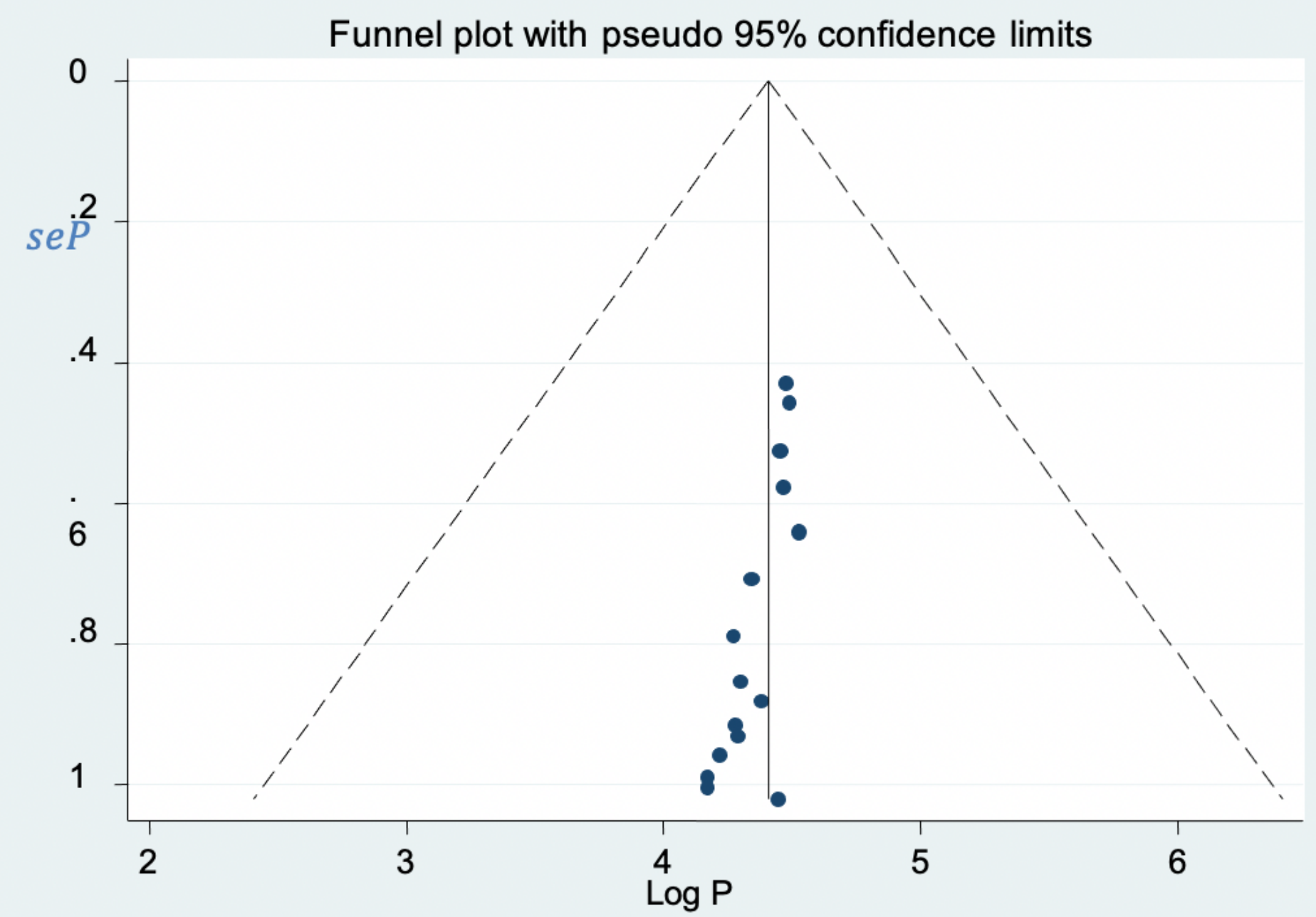

Figure 3

Funnel plot for adherence to highly active antiretroviral therapy 
Author

ES $(95 \% \mathrm{Cl}) \quad$ Weight

Molla et al./2018

Shewaye et al.2016

Wendwesen et al./2017

Abadiga/2019

Overall $(\mathrm{I}$-squared $=51.8 \%, p=0.101)$

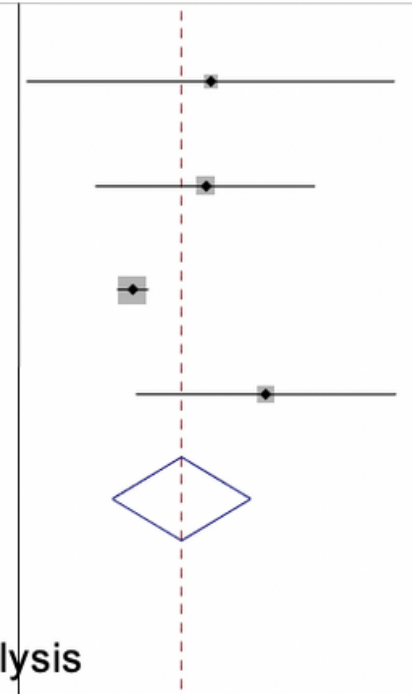

$3.65(1.06,12.59) 11.06$

$3.52(1.68,7.37) 22.15$

$2.15(1.94,2.39) 48.65$

$5.27(2.20,12.62) 18.15$

$2.99(1.88,4.77) 100.00$

NOTE: Weights are from random effects analysis

1

20

Figure 4

The effect of serostatus disclosure on adherence to highly active antiretroviral therapy

\section{Supplementary Files}

This is a list of supplementary files associated with this preprint. Click to download.

- PRISMA2009checklist.doc 